\title{
Altered hypothalamic DNA methylation and stress-induced hyperactivity following early life stress
}

\author{
Eamon Fitzgerald ${ }^{1,5^{*}} \mathbb{D}$, Matthew C. Sinton ${ }^{1}$, Sara Wernig-Zorc ${ }^{2}$, Nicholas M. Morton ${ }^{1}$, Megan C. Holmes ${ }^{1}$, \\ James P. Boardman ${ }^{3,4}$ and Amanda J. Drake ${ }^{1}$
}

\begin{abstract}
Exposure to early life stress (ELS) during childhood or prenatally increases the risk of future psychiatric disorders. The effect of stress exposure during the neonatal period is less well understood. In preterm infants, exposure to invasive procedures is associated with altered brain development and future stress responses suggesting that the neonatal period could be a key time for the programming of mental health. Previous studies suggest that ELS affects the hypothalamic epigenome, making it a good candidate to mediate these effects. In this study, we used a mouse model of early life stress (modified maternal separation; MMS). We hypothesised MMS would affect the hypothalamic transcriptome and DNA methylome, and impact on adult behaviour. MMS involved repeated stimulation of pups for $1.5 \mathrm{~h} /$ day, whilst separated from their mother, from postnatal day (P) 4-6. 3'mRNA sequencing and DNA methylation immunoprecipitation (meDIP) sequencing were performed on hypothalamic tissue at P6. Behaviour was assessed with the elevated plus, open field mazes and in-cage monitoring at 3-4 months of age. MMS was only associated with subtle changes in gene expression, but there were widespread alterations in DNA methylation. Notably, differentially methylated regions were enriched for synapse-associated loci. MMS resulted in hyperactivity in the elevated plus and open field mazes, but in-cage monitoring revealed that this was not representative of habitual hyperactivity. ELS has marked effects on DNA methylation in the hypothalamus in early life and results in stress-specific hyperactivity in young adulthood. These results have implications for the understanding of ELS-mediated effects on brain development.
\end{abstract}

Keywords: Early life stress, DNA methylation, Behaviour, Hypothalamus, Brain development, Preterm birth

\section{Introduction}

Experiencing early life stress (ELS) has been associated with an increased risk of psychiatric disorders including depression and anxiety in adulthood [1-3]. Individuals with a psychiatric disorder who were exposed to ELS are also less likely to respond well to treatment compared to those who were not $[4,5]$, perhaps indicating distinct

\footnotetext{
*Correspondence: eamon.fitzgerald@mcgill.ca

${ }^{1}$ University/British Heart Foundation Centre for Cardiovascular Science, University of Edinburgh, The Queens Medical Research Institute, 47 Little France Crescent, Edinburgh EH16 4TJ, UK

Full list of author information is available at the end of the article
}

mechanisms by which ELS can program future outcomes. A growing number of studies have reported ELS during childhood increases the risk for future psychiatric disorders $[6,7]$ and there are well-described long-term adverse consequences of prenatal exposure to maternal stress on mental health in offspring [8-10]. However, less is known about the long-term effects of ELS experienced specifically during the neonatal period. Most studies addressing stressors during the perinatal period have been undertaken in babies born preterm (birth at less than 37 weeks of gestation), with previous studies suggesting that stressful events such as exposure to painful 
procedures can affect brain development [11] and programme future stress responses [12].

One potential mechanism by which ELS may act is through programming of the HPA axis [13] and studies of ELS in animal models have described altered stress reactivity, neuronal activation and differences in DNA methylation within the hypothalamus [14-17], which is a key mediator of the ELS response $[17,18]$. Such studies have led to the proposal that changes in DNA methylation may at least partially mediate the effects of ELS, through influencing transcriptional events [19]. Moreover, several stress-related stimuli including glucocorticoids [20] and neuronal activity can affect DNA methylation [21]. In humans, changes in DNA methylation have been seen in post-mortem hippocampal tissue from individuals exposed to ELS [22] and peripheral DNA methylation around the FKBP5 gene has been proposed to mediate the response to ELS in humans [23].

To better understand the influence of ELS on neurodevelopment and to dissect the underlying mechanisms, animal models have been used [24]. Various ELS models, including maternal separation and altered maternal care have been associated with an array of different phenotypes, including effects on the hypothalamic-pituitaryadrenal (HPA) axis and vulnerability to adult stress [24]. Maternal separation is the most common model of ELS which involves pup separation from the mother for $\geq 3 \mathrm{~h} /$ day for $\geq 10$ consecutive days however considering the mother is the sole source of nutrition during this time, nutritional deficits may confound any findings in this model as hypoglycemia is independently associated with impaired neurodevelopment in humans [25]. To avoid this we used a modified maternal separation paradigm (MMS) to model ELS, involving short periods $(1.5 \mathrm{~h} /$ day from postnatal day (P)4-P6 of brief maternal separation in combination with manual manipulation during the period of separation [26].

We hypothesised that MMS would result in perturbations of the hypothalamic transcriptome and DNA methylome and in altered stress-induced behaviour in adulthood. We tested this using a combination of candidate gene expression analysis (for genes involved in glucocorticoid signalling and DNA methylation), 3'mRNA sequencing and DNA methylation immunoprecipitation (meDIP) sequencing in the hypothalamus at P6 (immediately following MMS). We then performed behavioural assessment using the elevated plus maze (EPM), open field (OF) and in-cage behavioural analysis of habitual activity at 3-4 months of age in adult male mice. We found that MMS associates with profound changes in hypothalamic DNA methylation in the neonatal period and with a stress-specific hyperactive phenotype in adulthood.

\section{Methods and materials}

\section{Animals}

Experiments were carried out in accordance with University of Edinburgh guidelines and the UK Home Office Animals (Scientific Procedures) Act 1986. Adult C57/ Bl6 mice (Harlan, UK) had ad libitum access to chow (Special Diets Services, Essex, UK) and water (lights on 07:00-19:00, temperature $22{ }^{\circ} \mathrm{C}$ ). For mating, 2 females and 1 male were kept per cage. Dams were checked daily for new litters with P0 designated as the day of birth. Mice were weaned at P21 with littermates housed together. Neonatal experiments consisted of $n=10 /$ group (10 independent litters), unless otherwise stated. Adult experiments were performed on $n=11$ /group (11 independent litters) for biochemistry, elevated plus maze (EPM), open field (OF) and tail suspension and $n=7$ for in-cage behavioural analysis.

\section{Modified maternal separation (MMS) and behavioural testing}

At P3, the litters were reduced leaving 4 male pups only. Within a litter, two males were randomly assigned to the control group and two to MMS. As previously described [26], MMS was performed between 1330 and 1500 daily from P4-P6 in a different room to their resident holding room. MMS pups were placed on a heating pad adjacent to the home-cage and for $1.5 \mathrm{~h}$, pups were gently moved to the supine position whenever they returned to a prone position. Pups were then returned to the home-cage. Pups were weighed daily; weights were normalised to P4 weight.

Immediately after MMS on P6, one cohort was killed by decapitation. Trunk blood was collected, and blood glucose measured immediately using the AccuCheck Performa Glucometer (Roche, UK). Whole blood was collected in EDTA-coated tubes (Sarstedt, Germany) and plasma isolated and stored at $-80{ }^{\circ} \mathrm{C}$. Whole brains were extracted and the hypothalamus dissected using the optic chiasm and the mamillary body recess as landmarks. Tissue was snap-frozen on dry ice and stored at $-80{ }^{\circ} \mathrm{C}$.

A second cohort of mice was weaned at P21, with control and MMS littermates housed together. Behavioural testing was performed at P90-P100. The EPM was used as described [27]. Mice were placed in the centre zone facing the open arm and left to explore the maze for $5 \mathrm{~min}$. The OF test was carried out as described [28], $24 \mathrm{~h}$ after the EPM. Mice were placed in the centre of the OF and allowed to explore for $5 \mathrm{~min}$. Recording and analyses were performed automatically using the AnyMaze software (AnyMaze, Dublin). One hour after the OF, tail suspension testing was performed as described [29] for 6 min with the tester hidden. Recordings were analysed for time immobile with the investigator blinded to group. 
At P120-P130, in-cage behaviour was analysed using the TSE-systems PhenoMaster (TSE-Systems, Germany). Mice were single-housed for 4 days for acclimatisation and then introduced into a fresh home-cage for testing. The mice were allowed to adjust to the novel environment for $24 \mathrm{~h}$ before measurements were taken. Activity measurements were automatically recorded through sensors over two consecutive 24-h periods, using detectors along the $\mathrm{x}$ - and $\mathrm{y}$-planes. Data were averaged across 2 consecutive $24-\mathrm{h}$ periods. Animals were killed by cervical dislocation. The brain was removed, leaving the pituitary gland in the skull for collection. The brain was then divided along the midline and the cortex was resected before hippocampal removal. The body cavity was then opened and the adrenal gland isolated from any surrounding fat. Tissue was frozen on dry ice and stored at $-80^{\circ} \mathrm{C}$.

\section{Corticosterone ELISA}

Blood samples were collected by tail venesection at 7 am and $7 \mathrm{pm}$ the day after the tail suspension test. Plasma corticosterone was analysed by ELISA (Enzo Life Sciences, Exeter).

\section{DNA/RNA extractions}

DNA/RNA were extracted from the same sample using the Qiagen All Prep DNA/RNA Mini Kit (Qiagen, Manchester).

\section{Reverse transcription and quantitative PCR}

$1 \mu \mathrm{g}$ of RNA was DNase treated with RQ1 RNase-free DNase (Promega, Hampshire). Reverse transcription was performed with the Applied Biosystems RT kit (Thermo Fisher Scientific, UK) in a G-Storm Thermocycler (Akribis Scientific Limited, Cheshire). qPCR primers were designed using the UPL assay design centre and cDNA samples analysed on a Roche LightCycler 480, normalised to the expression of the housekeeping gene $T B P$. Primers are listed in Additional file 1: Table S1.

\section{3'mRNA sequencing}

For 3'mRNA sequencing, 6 samples were randomly selected/group. Sequencing was performed at the Wellcome Trust Clinical Research Facility (University of Edinburgh). Library preparation was done using the QuantSeq 3'mRNA-Seq Library Prep Kit (Lexogen, Austria) and templates prepared using the Ion PI Hi-Q OT2 200 kit (Thermo Fisher Scientific, UK). Sequencing was performed using the Ion PI Chip Kit v3 (Thermo Fisher Scientific, UK), 12 samples/chip with an average of 7,822,219 reads/sample generated. This depth of sequencing has previously been shown sufficient for differential expression analysis [26, 30, 31]. The Ion Hi-Q
Sequencing 200 Kit (Thermo Fisher Scientific, UK) and the Ion Proton platform were used for analysis. For data analysis, raw $\mathrm{pH}$ DAT files were converted to flow signals and aligned to the mm10 reference genome in an automated workflow (Torrent Suite v5.2.0). Analysis was performed using Galaxy [32] and Degust software. Gene Ontology (GO) analysis was carried as described [33, 34], using genes with a $\log$ fold change $(\operatorname{logFC})>1.5[35,36]$. Transcription factor enrichment analysis was performed using oPOSSUM-3 software, with a Fisher score $<7$ and a Z-score $<10$ taken as significant enrichment [37]. Data are available through the Gene Expression Omnibus (GSE147375).

\section{DNA methylation immunoprecipitation and sequencing}

For DNA methylation immunoprecipitation (meDIP) sequencing, three pooled samples/group were used. These 3 pooled samples were generated by randomly allocating the 10 independent samples/group into 3 groups, before sequencing with the Ion Proton platform [38]. This was done to increase biological diversity across sequenced samples. A mean read length of 133-144 bp and 24,288,817-34,030,252 reads/sample was achieved. Reads were aligned to the $\mathrm{mm} 10$ genome using Torrent Suite v5.2.0. Aligned reads were sorted using SAMtools, before calling peaks using MACS2 (v2.1.1) -f BAM broad -broad-cutoff $0.05-\mathrm{B}-\mathrm{g}$ hs, over corresponding inputs [39]. To detect differentially methylated regions (DMRs), we used Diffbind with DESeq2 and edgeR [40]. DMRs were assigned to genes and other genomic features using the HOMER (v4.8) annotatePeaks tool [41]. Data were normalised to a pooled input for each group and subtracted from an IgG control. Sequencing data are available through the Gene Expression Omnibus (GSE146892).

\section{Statistical analysis}

Statistical analyses were performed using IBM SPSS software version 24 . Independent $\mathrm{t}$-tests were used for comparisons between control and MMS at a single timepoint. Repeated measures ANOVA was used for the comparisons between control and MMS at multiple time-points (i.e. AM and PM). For all experiments a p-value or FDR of 0.05 was taken as statistically significant.

\section{Results \\ MMS is not associated with early alterations in weight, glucose or plasma corticosterone}

In agreement with our previous report, there were no differences in weight gain (t-statistic $=-0.49, p=0.62$ for area under the curve, $\mathrm{df}=18$ ) (Fig. 1A) [26]. MMS also had no effect on blood glucose ( $\mathrm{t}$-statistic $=-0.11$, $p=0.91, \mathrm{df}=10$ ) (Fig. 1B) or plasma corticosterone 
A
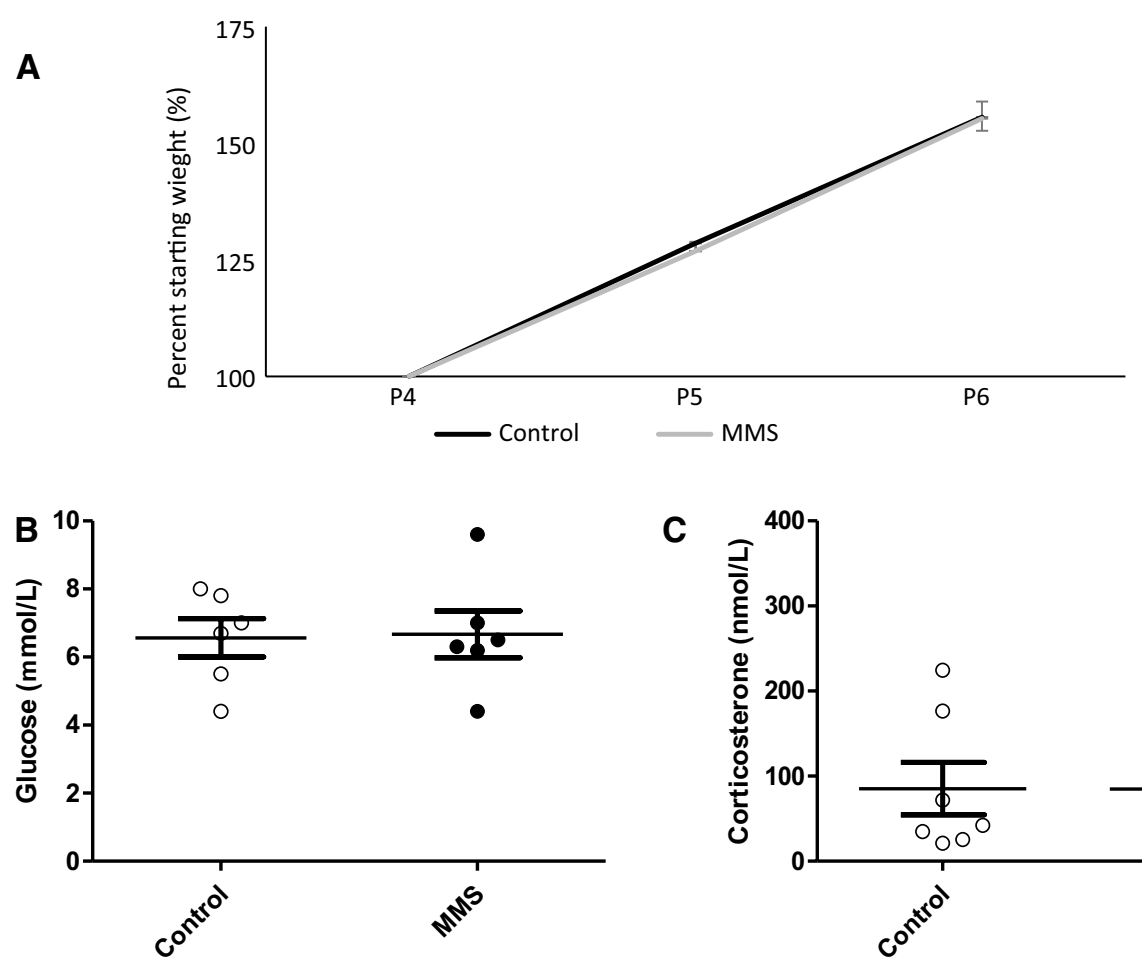

C

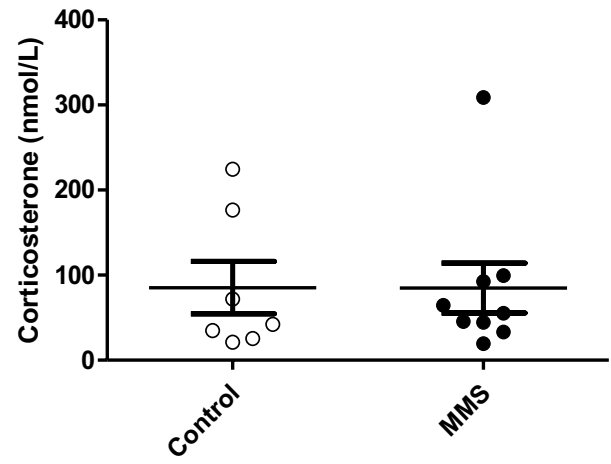

D

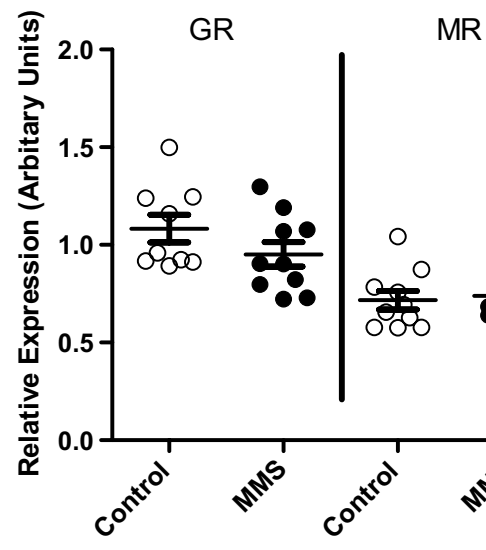

"QR

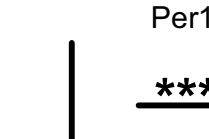

Per1

DNMT1

DNMT3a
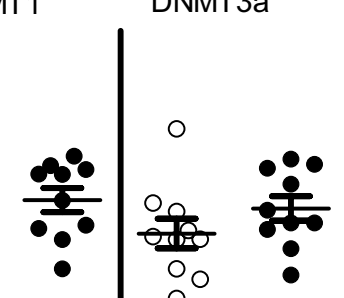

Fig. 1 MMS is not associated with alterations in weight gain, blood glucose or plasma corticosterone, but is associated with changes in candidate gene expression in the hypothalamus. A There was no difference in weight gain between control (black solid line) and MMS (orange dashed line) groups during MMS ( $p=0.62$ for area under the curve, $\mathrm{df}=18), n=10 /$ group. Pup weight was standardised to $100 \%$ at the P4 timepoint. There were no differences between control (clear circles) and MMS (black filled circles), in (B) blood glucose $(p=0.91)(n=6 / \mathrm{group}, \mathrm{df}=10)$ or $(\mathbf{C})$ plasma corticosterone concentrations ( $p=0.993, \mathrm{df}=14$ ) immediately following MMS ( $n=7$ and 10/group). D Following a Bonferroni correction for multiple comparisons the threshold for statistical significance was set at $p<0.01$. MMS was associated with increased mRNA expression of Per1 $(p=0.009, \mathrm{df}=18)$ but DNMT1 $(p=0.03, \mathrm{df}=19)$ fell marginally outside this threshold. There were no differences in the expression of $\mathrm{GR}(p=0.36$, $\mathrm{df}=17), \operatorname{MR}(p=0.77, \mathrm{df}=18)$ or DNMT3a $(p=0.21, \mathrm{df}=18), n=10 /$ group. All statistical comparisons were made by independent t-test. Error bars indicate standard error of the mean

concentrations $\quad(\mathrm{t}$-statistic $=0.009, \quad p=0.99, \quad \mathrm{df}=14)$ (Fig. 1C) between groups. Removal of the apparent outlier from the MMS group in Fig. 1C does not change the statistical interpretation of the results.
MMS associates with early changes in hypothalamic gene

\section{expression}

Analysis of hypothalamic expression of genes involved in glucocorticoid signalling and DNA methylation revealed increased expression of the glucocorticoid 
(See figure on next page.)

Fig. 2 3'mRNA sequencing of the hypothalamic transcriptome reveals only subtle changes associated with MMS. 6 samples were sequenced per group. A Volcano plot showing differential gene expression between groups, genes with a logFC greater than 1.5 are coloured blue (decrease) or red (increase). Only 1 gene (D630033011Rik) had an FDR > 0.05. B Gene Ontology analysis of genes with a logFC $>1.5$ (i.e. those coloured blue or red in A) for cellular component (pink), biological process (yellow) and molecular function (green). C Gene expression patterns, from control (clear circles) and MMS (black filled circles), identified from 3' mRNA sequencing and Gene Ontology were validated using qPCR. FOS was enriched in the Gene Ontology term "Ligand-gated cation channel activity" and NR4A3 was identified from the enriched term "DNA-binding transcription activator activity, RNA polymerase II-specific", in the biological process category. Both FOS $(p>0.001, \mathrm{df}=17)$ and NR4A3 $(p=0.004, \mathrm{df}=16)$ were significantly increased in expression following MMS

responsive gene Period 1 (Per 1$)$ (t-statistic $=-7.9$, $p=0.009, \mathrm{df}=18)$, which is associated with circadian rhythms, and there was a point difference in $D N A$ methyltransferase 1 (DNMT1) expression, which did not pass the corrected $\mathrm{p}$-value threshold ( $\mathrm{t}$-statistic $=-$ $2.28, p=0.03, \mathrm{df}=19$ ) (Fig. 1D). There were no changes in the expression of the glucocorticoid receptor (GR) $(\mathrm{t}$-statistic $=0.942, p=0.36, \mathrm{df}=17)$, mineralocorticoid receptor $(M R)$ (t-statistic $=-0.3, p=0.77, \mathrm{df}=18)$ or DNA methyltransferase $3 a(D N M T 3 a)$ (t-statistic $=-$ $1.3, p=0.21, \mathrm{df}=18$ ).

Next we used 3' mRNA sequencing to evaluate the whole hypothalamic transcriptome. This method has been shown to yield comparable differential expression results to that of traditional RNA sequencing methods, but with a greatly reduced sequencing depth [30, 31]. Analysis of 3'mRNA sequencing data identified only one gene (D630033O11Rik, labelled in Fig. 2A) as differentially expressed $(\mathrm{FDR}<0.05)$. Multi-dimension scaling (MDS) showed poor clustering of groups (Additional file 2: Fig. S1A). GO analysis of genes with $\log F C>1.5$ [35, 36] (Fig. 2A: blue=downregulated, red=upregulated) revealed enrichment for terms associated with "DNA binding RNA polymerase specific" and "Ligandgated cation channel activity" within the molecular function category (Fig. 2B). Genes identified in these enrichment terms with the greatest $\operatorname{logFC}$ were $N R 4 A 3$ and FOS; upregulation of both genes was validated by qPCR (Fig. 2C) (NR4A3; t-statistic $=-3.34, p=0.004$, $\mathrm{df}=16$ and FOS; t-statistic $=-6.37, p>0.001, \mathrm{df}=17)$. Transcription factor binding enrichment analysis of genes with $\operatorname{logFC}>1.5$ showed enrichment in motifs associated with factors with neurodevelopmental functions (Additional file 2: Fig. S1B) including Nuclear Factor kappa B (NFkB) [42], Hypoxia Inducible Factor (HIF) $1 \alpha$ [43] and Krüppel-like factor 4 (KLF4) [44, 45]. See Additional file 1: Table S2 for a full list of genes with a $\operatorname{logFC}$ greater than 0.5 .

\section{MMS associates with early alterations in hypothalamic DNA methylation}

Previous research has shown ELS can affect DNA methylation [17]. As such, we postulated that DNA methylation might be affected following MMS. We investigated this using meDIP sequencing within the hypothalamus. We identified 13,000 DMRs across the genome. Principal component analysis showed a distinct effect of MMS on DNA methylation (Fig. 3A). All DMRs are represented in the heatmap depicted in Fig. 3B, clustered by Euclidian distance and within group samples were highly correlated (Fig. 3C). Next, we identified DMRs associated with protein coding regions (Fig. 3D). GO analysis revealed enrichment for terms associated with various synaptic elements (Fig. 3E). Differential methylation analysis was performed using DESeq2, but there was a substantial overlap of DMRs identified using an alternative method (edgeR) (Additional file 2: Fig. S2A). There was no correlation between DMRs associated with protein coding regions and transcript expression (Additional file 2: Fig. S2B). In particular, although DNA methylation in promoter regions is classically associated with gene expression [46], fewer than 20 promoter DMRs were identified, and these were not associated with transcript expression. See Additional file 1: Table S3 for a full list of DMRs.

\section{MMS is associated with hyperactivity in the elevated plus maze (EPM) and open field maze (OF) but normal habitual in-cage movement at 3-4 months}

Representative track plots for control and MMS mice in the EPM are shown in Fig. 4A, B. Mice exposed to MMS travelled further in the EPM (t-statistic $=-2.43, p=0.02$, $\mathrm{df}=20$ ) (Fig. 4C) but there were no differences in the time spent in open (t-statistic $=-0.76, p=0.46, \mathrm{df}=20$ ), closed (t-statistic $=1.41, p=0.28, \mathrm{df}=20)$ or centre (t-statistic $=-1.02, p=0.32, \mathrm{df}=20)$ areas (Fig. $4 \mathrm{D})$. MMS mice also had a higher average speed (t-statistic $=-2.46, p=0.02, \mathrm{df}=20)$ and total mobile time $(\mathrm{t}$-statistic $=-2.49, p=0.02, \mathrm{df}=20)$ (Additional file 2: Fig. 3A and B). MMS mice also travelled further in the closed arm (t-statistic $=-2.1, p=0.048, \mathrm{df}=20)$, with no difference in visit duration (t-statistic $=1.94, p=0.06$, $\mathrm{df}=20$ ) (Additional file 2: Fig. $3 \mathrm{C}$ and $\mathrm{D}$ ), while there were no differences in distance travelled in the open arms (t-statistic $=-0.9, p=0.38, \mathrm{df}=20)$ or in visit duration (t-statistic $=0.13, p=0.90, \mathrm{df}=20$ ) (Additional file 2: 


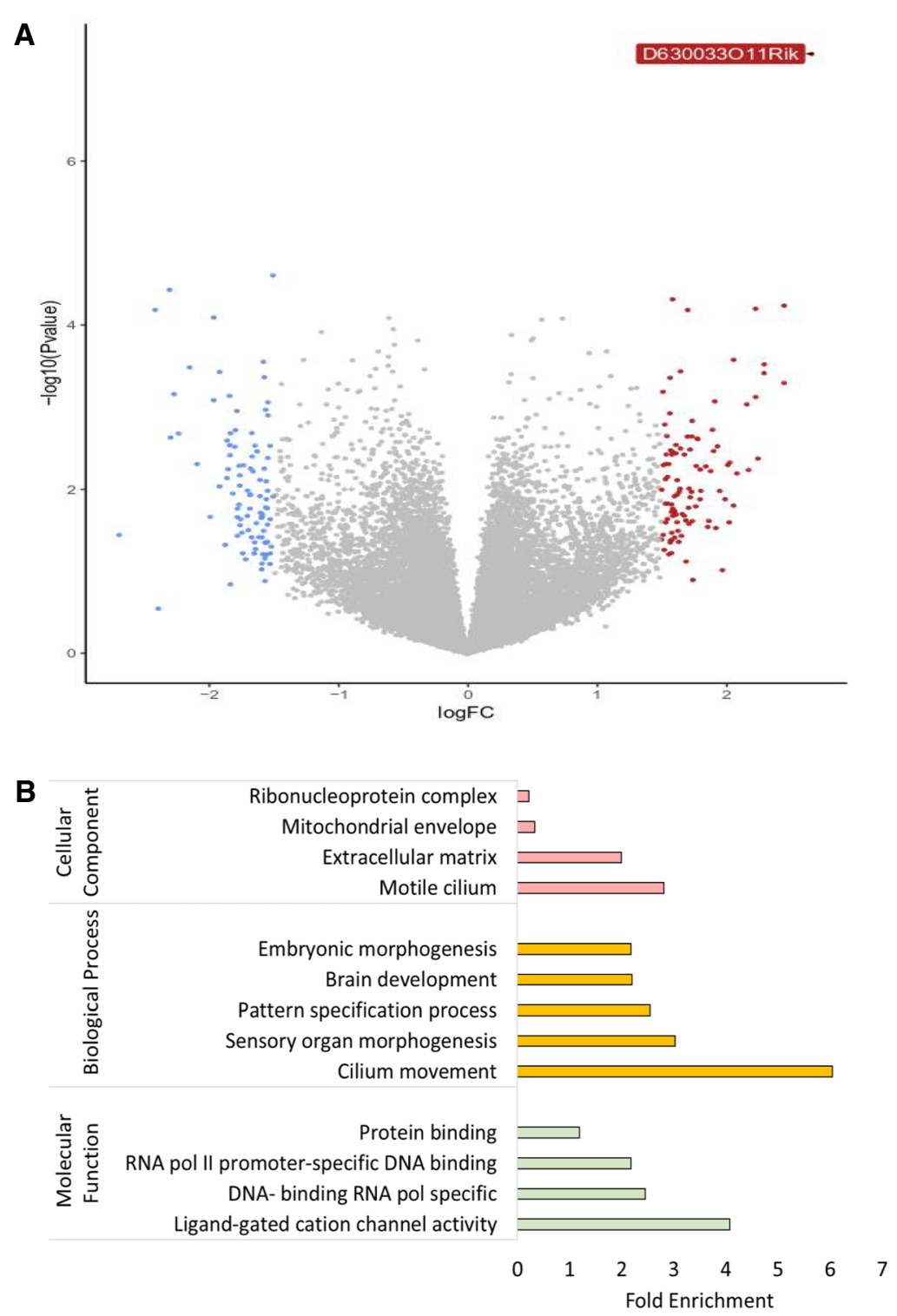

C

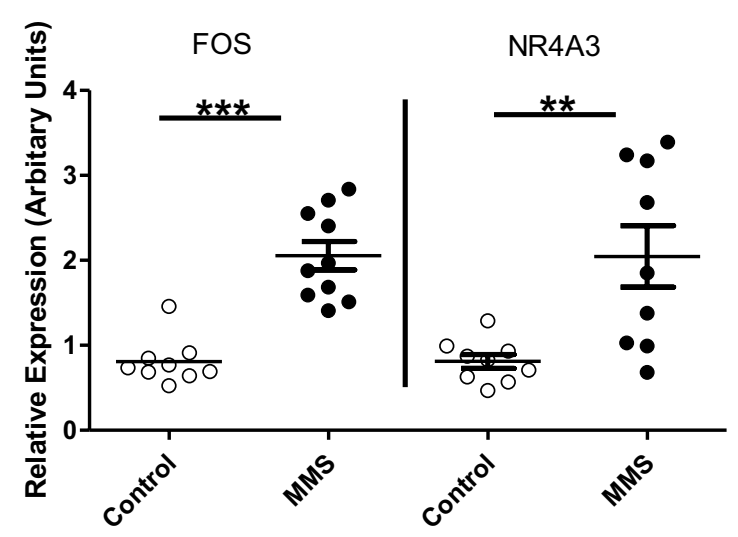

Fig. 2 (See legend on previous page.) 

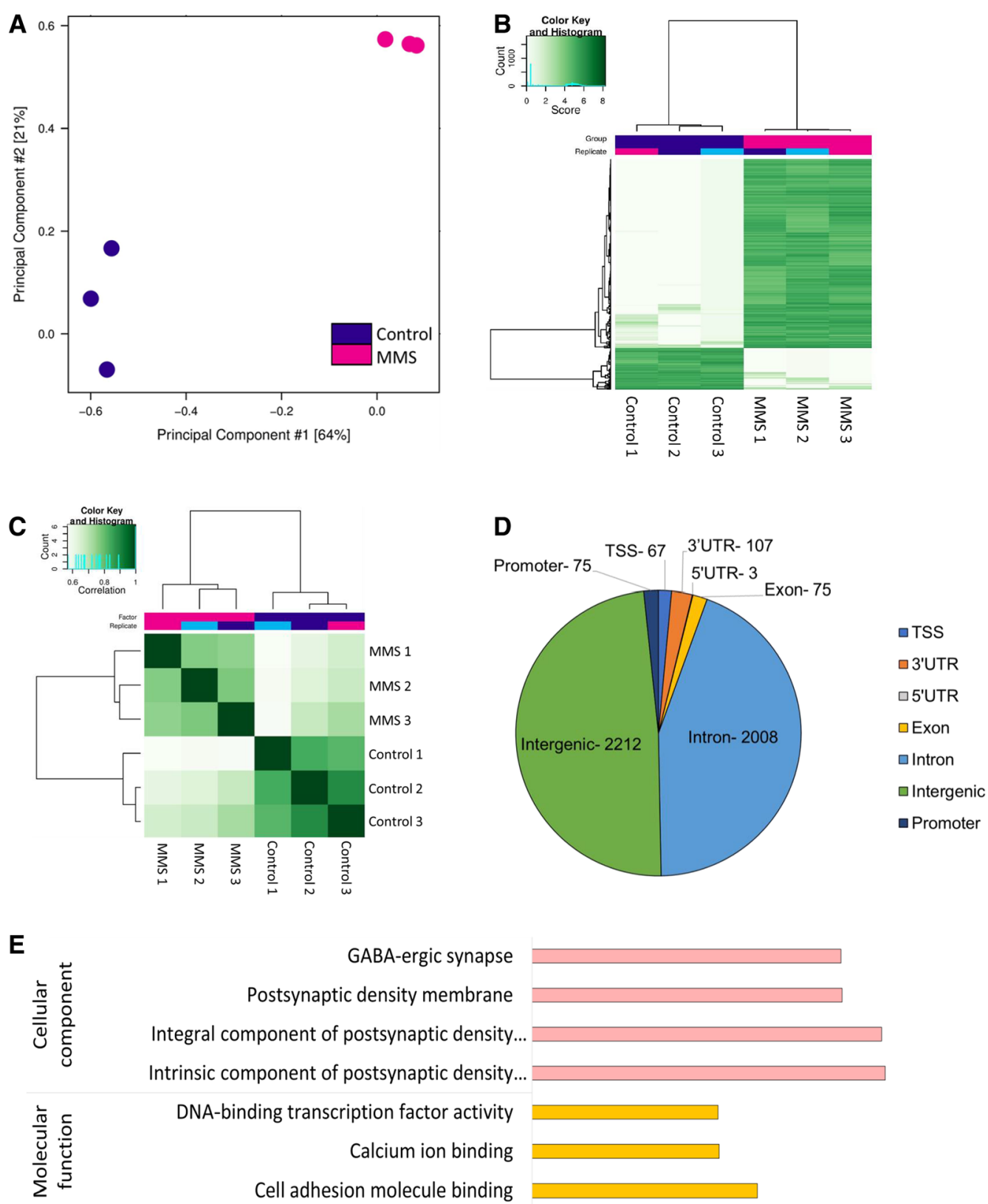

DNA-binding transcription factor activity

Calcium ion binding

Cell adhesion molecule binding

Neuron migration

$\overline{0}$
$\frac{0}{00}$
0
$\frac{0}{0}$
$\frac{0}{0}$

Cell-cell adhesion via plasma-membrane adhesion...

Homophilic cell adhesion via plasma membrane...

Regulation of synapse assembly

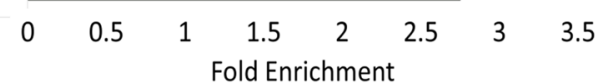

Fig. 3 Widespread alterations in DNA methylation within the hypothalamus following MMS using meDIP sequencing. 3 samples were sequenced per group. A Principal component analysis of differentially methylated regions shows distinct clustering of control (blue) and MMS (pink) groups. Principal components 1 and 2 accounted for $64 \%$ and $21 \%$ of variance in the dataset, respectively. B Heatmap of all DMRs throughout the genome with an FDR $<0.05$, which are clustered by Euclidian distance. C Correlation map of control and MMS samples following meDIP sequencing clustered by Euclidian distance. D Catalogue of the DMRs associated with protein coding regions. Numbers indicate numbers of DMRs associated with that region. (E) Gene Ontology analysis of differentially methylated sites (FDR $<0.05)$ associated with protein coding regions. Terms for cellular component (pink), molecular function (yellow) and biological processes (green) are shown. Notably, there is enrichment of synapse-associated terms under cellular component and biological processes 
(See figure on next page.)

Fig. 4 MMS is associated with hyperactivity in the elevated plus (EPM) and open field (OF) maze. (A and B) Representative track plots for control and MMS groups in the EPM, with the open and closed arms of the maze indicated in $\mathbf{A}$. C The MMS group travelled further during the EPM ( $n=11 /$ group) ( $p=0.02, \mathrm{df}=20)$, but there were no differences in the time spent in the open $(p=0.457, \mathrm{df}=20)$, closed $(p=0.267, \mathrm{df}=20)$ or centre $(p=0.32, \mathrm{df}=20)$ areas $\mathbf{D}$. E and $\mathbf{F}$ Representative track plots for control and MMS groups in the OF with the inner and outer zones indicated in E. G The MMS group travelled further in the $\mathrm{OF}(n=11 /$ group) $(p=0.02, \mathrm{df}=21)$ and spent similar amounts of time in the inner $(p=0.07, \mathrm{df}=20)$ and outer zones $(p=0.07, \mathrm{df}=20)(\mathbf{H})$. Independent t-tests were used for $\mathbf{C}, \mathbf{D}, \mathbf{G}$ and $\mathbf{H}$. Error bars indicate standard error of the mean

Fig. 3E and F). Representative track plots for the control and MMS groups in the OF are shown in Fig. 4E and 4F. MMS mice travelled further ( $\mathrm{t}$-statistic $=-2.57, p=0.02$, $\mathrm{df}=21$ ) (Fig. 4G) but did not show altered preference for the inner (t-statistic $=-1.91, p=0.07, \mathrm{df}=20)$ and outer zones (t-statistic $=1.91, p=0.07, \mathrm{df}=20)($ Fig. $4 \mathrm{H})$. MMS mice also moved faster (t-statistic $=-2.57, p=0.02$, $\mathrm{df}=20)$ and spent more time mobile (t-statistic $=-2.56$, $p=0.02, \mathrm{df}=20$ ) (Additional file 2: Fig. $4 \mathrm{~A}$ and B). MMS mice travelled further in the OF inner ( $\mathrm{t}$-statistic $=-$ 2.69, $p=0.02, \mathrm{df}=20$ ) and outer (t-statistic $=-2.15$, $p=0.04, \mathrm{df}=20)$ zones, with a shorter length of visit to the outer zone $(\mathrm{t}$-statistic $=2.11, p=0.048, \mathrm{df}=20)$ (Additional file 2: Fig. 4C-F). There were no differences between groups in time immobile ( $\mathrm{t}$-statistic $=-1.01$, $p=0.32, \mathrm{df}=20)$ during the tail suspension test (Additional file 2: Fig. 4G).

The EPM and OF constitute novel stressful environments. As such our next question was whether this hyperactivity was representative of higher habitual activity (used here to reference the animal's constitutive home cage activity, as opposed to the activity formally measured in the OF and EPM). or specifically related to the novel environment. In-cage behavioural monitoring using the TSE PhenoMaster system tracked movement over a 24-h period (two consecutive 24-h periods were averaged for each animal). Monitoring revealed no differences in habitual activity between groups in cumulative movement (Fig. 5), movement during light/dark phases $(p=0.25, f=1.40, \mathrm{df}=24)$ (Fig. $5 \mathrm{~B})$, or movement associated with grooming behaviours ( $\mathrm{t}$-statistic $=-$ $0.05, p=0.96$ and 0.73 , respectively, $\mathrm{df}=12$ ) (Additional file 2: Fig. $5 \mathrm{~A}$ and $\mathrm{B})$. As expected, there was, a significant effect of time $(p=0.003, f=10.57, \mathrm{df}=24)$ such that animals were more active during the dark phase (Fig. 5B). Detailed analysis of other habitual and circadian behaviour patterns showed no differences in food intake, calorie expenditure and fuel usage (Additional file 2: Fig. 5C-E). Finally, there were no differences in diurnal plasma corticosterone concentrations (main effect of MMS; $F=0.453$ and $p=0.506$, main effect of time (i.e. $\mathrm{AM} / \mathrm{PM}) ; \mathrm{F}=5.512$ and $\mathrm{p}=0.025$ interaction effect; $\mathrm{F}=1.37$ and $p=0.26)$, total body weight $(p=0.144)$, lean body mass $(p=0.553)$ or fat mass $(p=0.364)$.

\section{MMS does not associate with persistent changes in candidate gene expression or DNA methylation in the adult hypothalamus.}

We next evaluated the expression of genes associated with stress signalling in the adult hypothalamus. We identified no changes in the expression of $G R$ (t-statistic $=0.96, p=0.35, \mathrm{df}=15), \quad M R \quad(\mathrm{t}$-statistic $=0.31$, $p=0.76, \mathrm{df}=18), \operatorname{Per} 1$ (t-statistic $=0.26, p=0.80, \mathrm{df}=15)$ or FKBP5 (t-statistic $=0.36, p=0.72, \mathrm{df}=15) \quad($ Additional file 2: Fig. 6A). Further, there were no changes in the expression of stress-associated genes elsewhere in the HPA axis including the adrenal and pituitary glands (Additional file 2: Fig. 6B and C). We did however find changes in expression of the $G R$ (t-statistic $=-3.41$, $p=0.003, \mathrm{df}=18), F K B P 5$ (t-statistic $=-3.31, p=0.003$, $\mathrm{df}=18)$ and Per1 (t-statistic $=-3.29, p=0.004, \mathrm{df}=20)$ in the hippocampus (Additional file 2: Fig. 6D).

\section{Discussion}

We show that ELS is associated with profound early changes in the hypothalamic DNA methylome and with changes in stress-induced behaviour in young adulthood. Animal models can be useful in furthering our understanding of the long-term effects of ELS and in facilitating the dissection of underlying mechanisms, however the large differences in experimental design and behavioural outcomes make interpretation difficult [47]; indeed, previous studies using maternal separation paradigms have described conflicting effects on behaviour [47]. We used a modified model of maternal stress [26] involving shorter periods of separation and frequent manipulation during the separation, with the lack of effects on weight gain and blood glucose levels supporting that MMS is a mild stressor and that maternal care is maintained. We speculate that the active manipulation component of MMS may lead to more consistent experience of the stress between pups and reduce heterogeneity in adult behavioural outcomes. Further, this model avoids hypoglycaemia as a confounder, which is important since hypoglycaemia is independently associated with atypical neurodevelopment [25].

Animal models of ELS have been associated with an array of behavioural phenotypes including alterations in anxiety-like behaviours [48], social interaction [49] and learning [50]. Previous studies have also hinted 
Fitzgerald et al. Epigenetics \& Chromatin $\quad$ (2021) 14:31

Page 9 of 14
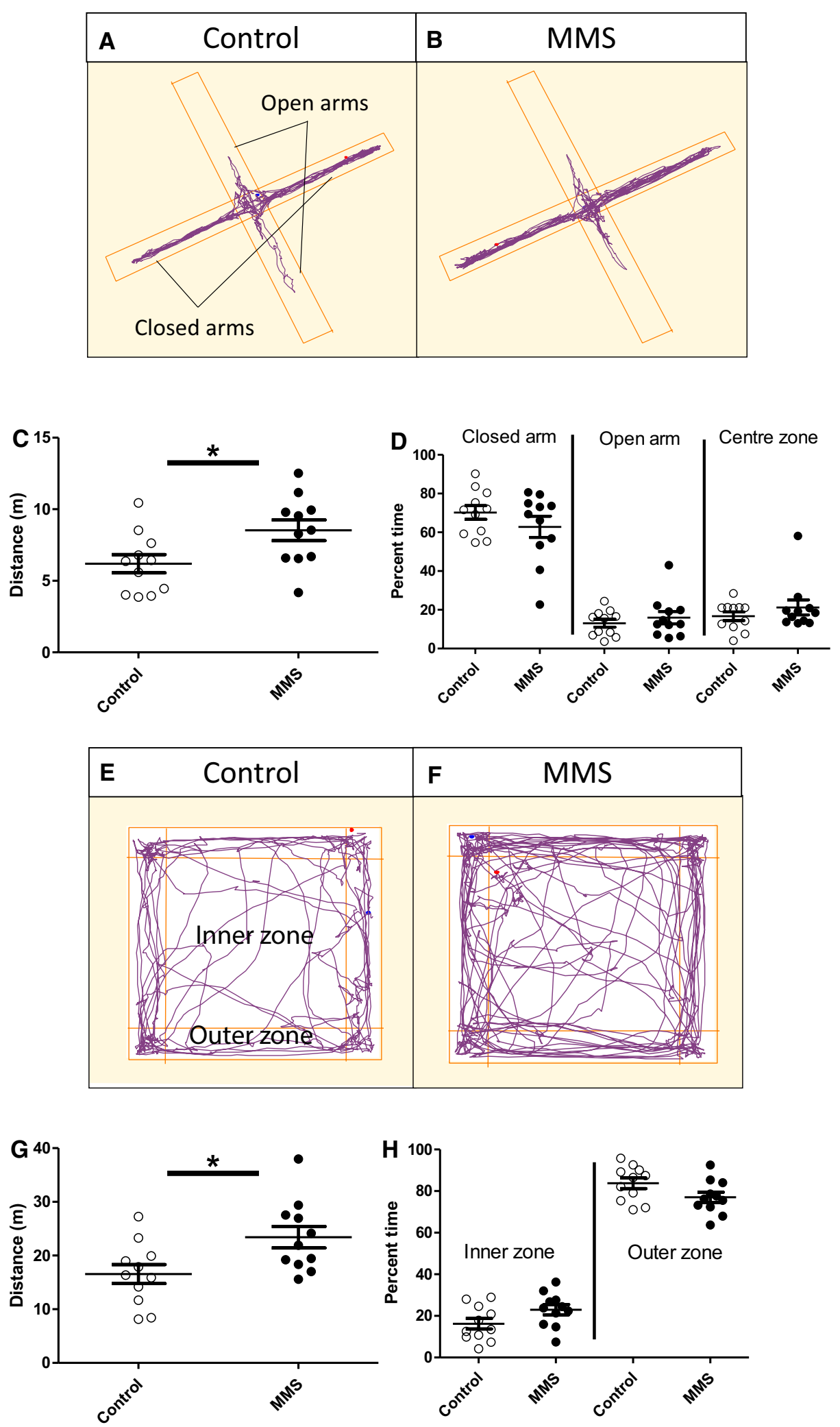

Fig. 4 (See legend on previous page.) 


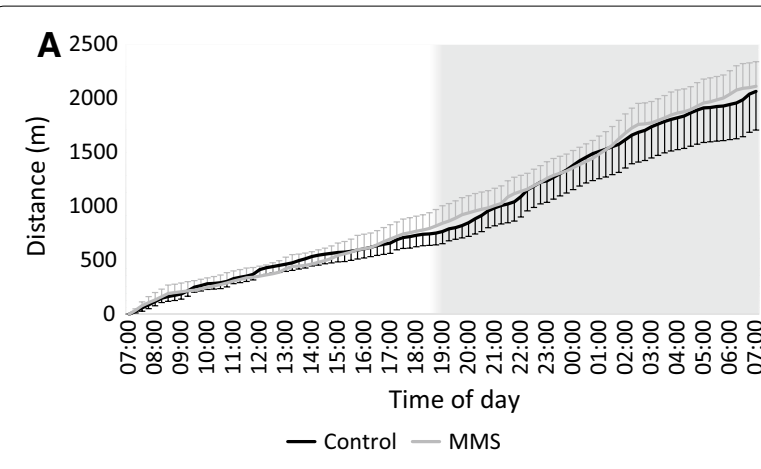

B

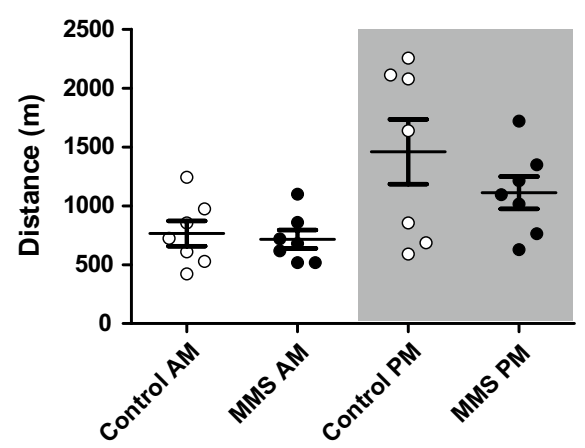

Fig. 5 No change in habitual activity associated with MMS. In-cage behavioural monitoring using the TSE PhenoMaster system tracked movement over a 24-h period (two consecutive $24-\mathrm{h}$ periods were averaged for each animal). A Cumulative distance travelled with respect to time of day, the light aspect of the graph indicates when the lights were on and the dark aspect indicates when the lights were off. B Total movement calculated for the light and dark phase (indicated by AM and PM, as well as the light and dark aspects) revealed no difference between the groups ( $p=0.25, f=1.40, \mathrm{df}=24)$ ( $n=7$ /group) and no interaction with time $(p=0.38, \mathrm{f}=0.79, \mathrm{df}=24)$ As expected, there was, a significant effect of time such that animals were active during the dark phase $(p=0.003, f=10.57, \mathrm{df}=24)$. A two-way ANOVA with repeated measures was used to assess statistical associations in $\mathbf{B}$. Error bars indicate standard error of the mean

at stress-specific effects on behaviour following ELS. For instance, ELS in rodents has been associated with reduced memory in the object recognition task [51] but increased memory following fear conditioning [52]. In this study we used in cage behavioural monitoring to demonstrate that the hyperactivity seen in the OF and EPM following MMS was not representative of habitual increased levels of activity and as such indicates a stress-specific hyperactive phenotype. This is important as abnormal stress responses are present in a variety of neurodevelopmental and psychiatric disorders, including anxiety disorders [53], ASD [54], schizophrenia [55], bipolar disorder [56] and are also a consequence of ELS [6] and preterm birth (PTB) $[12,57,58]$. In humans, ELS has been associated with alterations in emotional regulation, reward processing, cognition and memory $[59,60]$. Both ELS [61, 62] and PTB are associated with an increased incidence of ADHD [63]. Therefore, a plausible interpretation of our findings is that the ELS associated with neonatal manipulation plays a role in programming future stress response and that this is one potential mechanism underpinning the development of psychiatric disorders.

DNA methylation is dynamic during human brain development [64] and perturbations in DNA methylation are associated with several neurodevelopmental disorders, including ASD [65], schizophrenia [66] and ADHD [67]. A number of studies have reported that ELS is associated with differences in DNA methylation at loci which may affect HPA axis feedback [24, 68, 69]. We found substantial changes in hypothalamic DNA methylation immediately after MMS, and although this was not associated with widespread differences in gene expression, we did find a transcriptional signature of increased neuronal activation and an enrichment of DMRs in synapse-associated genes. In the adult brain neuronal activity is a potent modifier of DNA methylation [21], and DNA methylation has crucial roles in regulating synapse-associated genes [70]. Thus, it is possible that MMS-induced neuronal signalling may be one mechanism driving the early methylation changes. Considering the dynamic nature of DNA methylation during brain development [64] and the important role of the hypothalamus in HPA axis regulation [18], it is also possible that these early changes could be involved in programming stress-specific hyperactivity in adulthood.

Glucocorticoids are a primary mediator of the stress response, but MMS did not result in increased plasma corticosterone concentrations at P6. The classic mechanism of glucocorticoid action involves transcriptional alterations following GR binding, and an initial candidate approach to assess gene expression revealed increased expression of the glucocorticoid sensitive gene and circadian regulator, Per1. However, transcriptome-wide analysis revealed minimal changes in gene expression, and transcription factor binding enrichment analysis did not show enrichment for glucocorticoid binding elements. This suggests a limited role for traditional glucocorticoidmediated transcriptional changes following MMS, in line with the well-characterised stress hyporesponsive period in neonatal rodents [71]. The lack of change in corticosterone in adulthood is perhaps not surprising given the lack of differences in the in-cage parameters and supports the suggestion that the observed behaviours are induced by exposure to a novel environment but are absent at rest. 
PTB is a profound early life stressor and is associated with an increased risk of neurodevelopmental and psychiatric disorders. This is of great importance for public health policy, since PTB accounted for $10.6 \%$ of births worldwide in 2014 [72] and the rate has increased annually since 2014 in the United States [73]. One of the major long-term consequences of PTB is cognitive impairment [74] and PTB is also closely associated with autism spectrum disorder (ASD) [75], schizophrenia [76], attention deficit hyperactivity disorder (ADHD) [63] and various psychiatric disorders [77]. In mice, brain development at birth is roughly equivalent to that of a human at 24 weeks post-conception and matures to term equivalence by P10 [78], so that the time-points utilised in this study are of relevance to neurodevelopmental time-points in infants born preterm and our findings may have significance for infants born preterm. We and others have shown alterations in DNA methylation at key neurodevelopmental loci in infants born preterm in comparison to term born infants [79] although by necessity these studies have been done in peripheral tissues and whether there are also differences in relevant brain areas is unknown. Of note, preterm infants are also at increased risk for ADHD [63, 80] and although the mechanisms linking PTB with ADHD are unknown, hypotheses which have been advanced include ELS and HPA axis dysregulation [63]. Whether ADHD following PTB is particularly responsive to novel environments is unknown.

The primary limitation of this study is the use of only male animals. We chose to focus on males initially since in humans, males are more sensitive to neonatal stress associated with painful procedures [12] and animal studies suggest prenatal or early life stress may preferentially affect behavioural outcome in males [47, 81, 82]. However, in humans and animal models females have an increased risk of depression and anxiety disorders in later life following childhood stress [83, 84]. As such, future studies should focus on the investigation of outcome in both sexes following MMS.

In this study we used meDIP seq to identify DMRs associated with MMS. Although there is generally good local correlation between methylated cytosine residues [85], validation of our findings in future studies using methods with higher resolution such as whole genome bisulphite sequencing will be important. Furthermore in this study, sequencing was carried out on bulk hypothalamic tissue at a single timepoint. Future experiments should prioritise investigation of the transcriptome and DNA methylome within individual nuclei and at cellular resolution. Understanding the persistence of the DNA methylation changes we outline in the neonatal period, into adulthood will also be an important future consideration. Exploring the causal relationship of neonatal changes in DNA methylation to subsequent behaviour through emerging experimental, locus-specific modulation of DNA methylation [86] also promises to provide many exciting insights. Finally, in this study we investigated the hypothalamus, as it is a core modulator of the HPA axis and thus stress responses. However, it is clear that complex behaviours resulting from ELS are the result of contributions from several brain areas and neural circuits, including those in corticolimbic and striatal brain regions $[87,88]$. Future studies should aim to evaluate these regions and to understand how they interact in the generation of complex behaviours in the context of ELS.

In conclusion, we have demonstrated differential methylation in the hypothalamus in the neonatal period and stress-induced hyperactivity in adulthood following ELS. We suggest that MMS is a useful model for the study of stress-associated alterations in brain development and may be of particular relevance to PTB.

\section{Supplementary Information}

The online version contains supplementary material available at https://doi. org/10.1186/s13072-021-00405-8.

Additional file 1: Table S1. List of GPCR primers and associated UPL probe used in this manuscript. Table $\mathbf{S} 2$ List of genes identified by $3^{\prime}$ mRNA sequencing with a logFC greater than 0.5. Table S3 List of DMRs identified by meDIP sequencing with an FDR less than 0.05 .

Additional file 2: Fig. S1. MDS plot and transcription factor binding enrichment analysis for 3'mRNA sequencing. A MDS plot for all sequenced samples (control-blue and MMS-orange). Dimension 1 accounted for $50 \%$ of the total variance in the dataset, while dimension 2 accounted for $15 \%$. B Transcription factor binding enrichment analysis using the oPOSSUM software, identifies transcription factors with binding sites overrepresented among genes which have a logFC > 1.5. Listed are the Fisher (clear bars) and Z scores (black bars) for each transcription factor. Statistical comparisons were done using an independent t-test. Error bars indicate standard error of the mean, $n=10$ /group. Fig. S2 meDIP sequencing. A Venn diagram of 2 methods of analysis for differential DNA methylation shows significant overlap between DESeq2 and edgeR. There were 493 and 7047 unique DMRs associated with the edgeR and DESeq2 methods, respectively, with 12,456 DMRss identified in both methods. B There was no correlation between DMRs (y-axis) and expression of corresponding genes (logFC $>0.5 ; x$-axis). Pearson correlation coefficient $0.07 ; p=0.36$. Figure S3 EPM. A The MMS group (black circles) moved faster than the control group (clear circles) $(p=0.02, \mathrm{df}=20)$. B The MMS group spent more time mobile $(p=0.02, \mathrm{df}=20)$, total test duration $300 \mathrm{~s}$. C The MMS group travelled further in the closed arm $(p=0.048, \mathrm{df}=20)$ but $\mathbf{D}$ there was no difference in the duration of each visit to the closed $\operatorname{arm}(p=0.06, \mathrm{df}=20)$. There were no differences in the distance travelled in the open arms of the maze $\left(E_{;} p=0.38, d f=20\right)$ or the average duration of visit to the open arms ( $F ; p=0.90, d f=20)$. All comparisons were made using an independent t-test. Error bars indicate standard error of the mean, $n=11 /$ group. Fig. S4 OF and tail suspension tests. A Animals in the MMS group (black circles) moved with a higher speed throughout the testing period when compared to controls (clear circles) $(p=0.02, \mathrm{df}=20$ ). B The MMS group spent more time mobile $(p=0.02, \mathrm{df}=20)$, total test time $300 \mathrm{~s}$. C The MMS group travelled further in the outer zone $(p=0.04$, $\mathrm{df}=20$ ). $\mathbf{D}$ The average visit to the outer zone was shorter in the MMS group ( $p=0.048, d f=20$ ). $\mathbf{E}$ The MMS group also travelled further in the inner zone $(p=0.02, \mathrm{df}=20)$. $\mathbf{F}$ There was no difference between groups with respect to duration of visit to the inner zone $(p=0.48, \mathrm{df}=20)$. $\mathbf{G}$ In the tail suspension test, there was no difference in total immobile 
time between groups ( $p=0.32, \mathrm{df}=20$ ). Total length of testing $360 \mathrm{~s}$. All comparisons were made using independent t-tests. Error bars indicate standard error of the mean, $n=11$ / group. Fig. S5. In cage analysis reveals no statistical differences in in-cage activities, feeding behaviour and calorie expenditure following MMS. There were no differences in (A) $x$-axis or (B) $y$-axis related grooming behaviour as quantified by laser beam breaks in the specified plane ( $p=0.96$ and 0.73 , respectively, $\mathrm{df}=12)$. C There was no difference in food intake quantified as total feeding during lights on (control AM and MMS AM) and lights off (control PM and MMS PM). There was a significant effect of time ( $p>0.001)$, but no effect of MMS $(p=0.75)$ or interaction between time and MMS $(p=0.15)$. E There was no difference in calorie expenditure normalised for lean body mass $(p=0.99$, $\mathrm{df}=12)$ or in fuel usage as indicated by respiratory exchange ratio $\left(\mathrm{E}_{;}\right.$ control (black line) and MMS (grey line)) over $24 \mathrm{~h}$ (error bars indicate standard error of the mean). $\mathrm{N}=7 /$ group. Fig. $\mathbf{S 6}$ No changes in candidate gene expression in the hypothalamus, adrenal or pituitary glands but there are changes in gene expression in the hippocampus at 4 months of age, following MMS. A There were no differences in expression of the GR $(p=0.35, \mathrm{df}=15), \mathrm{MR}(p=0.76, \mathrm{df}=18)$, Per1 $(p=0.80, \mathrm{df}=15)$ or FKBP5 $(p=0.72, \mathrm{df}=15)$ in the hypothalamus between control (clear circles) and MMS (black filled circles) mice at 4 months of age. $\mathbf{B}$ In the adrenal gland, there were no changes in gene expression for Cyp $11 b 1(p=0.35$, $\mathrm{df}=15), \operatorname{MC} 2 \mathrm{R}(p=0.72, \mathrm{df}=17)$ or $\operatorname{st} \operatorname{Ar}(p=0.80, \mathrm{df}=16)$ between the control (clear circles) and MMS (black filled circles) groups. C There were no changes in candidate gene expression in the pituitary gland for the $\operatorname{GR}(p=0.81, \mathrm{df}=20)$, the MR $(p=0.13, \mathrm{df}=19)$, FKBP5 $(p=0.92, \mathrm{df}=14)$, Per1 ( $p=0.09, \mathrm{df}=20)$ or POMC $(p=0.78, \mathrm{df}=18)$ between control (clear circles) and MMS (black filled circles) groups. $\mathbf{D}$ In the hippocampus, there was increased expression of $\mathrm{GR}(p=0.003, \mathrm{df}=18)$, FKBP5 $(p=0.003$, $\mathrm{df}=18)$ and Per $1(p=0.004, \mathrm{df}=20)$, but no change in expression of the $\operatorname{MR}(p=0.37, \mathrm{df}=19)$ or HSD1 $1 \mathrm{~b} 1(p=0.08, \mathrm{df}=20)$. All candidate gene expression was normalised to the expression of TBP. All statistical comparisons were made using independent t-tests; $n=7-11 /$ group. Error bars indicate standard error of the mean.

\section{Acknowledgements}

We would like to acknowledge the Wellcome Trust Clinical Research Facility at the Western General Hospital, University of Edinburgh for carrying out 3'RNA sequencing.

\section{Authors' contributions}

EF designed and carried out the experiments, analysed the data and wrote the manuscript. MCS, and SWZ analysed the data. NMM was involved with experimental design, data acquisition and analysis. MCH was involved with experimental design. JPB was involved with experimental design, data interpretation and manuscript formulation. AJD was involved with experimental design and wrote the manuscript. All authors contributed to the final version of the manuscript.

\section{Funding}

This work was funded by a PhD studentship (to EF) from Medical Research Scotland (PhD-878-2015), in collaboration with Aquila BioMedical (Edinburgh, UK) and a grant from the RS Macdonald Seedcorn Fund (to AJD and JPB), administered by Edinburgh Neuroscience. MCS was supported by a British Heart Foundation PhD studentship (FS/16/54/32730) and by the British Heart Foundation Centre of Research Excellence. SW-Z was funded by the Deutsche Forschungsgemeinschaft (SFB960). NMM was supported by a Wellcome Trust New Investigator Award (100981/Z/13/Z). MCH was supported by the Wellcome Trust (WT079009). JPB was supported by the MRC Centre for Reproductive Health Centre Grant (MRC G1002033). AJD was supported by the British Heart Foundation Centre of Research Excellence, University of Edinburgh. All sequencing was carried out at the Wellcome Trust Clinical Research Facility at the Western General Hospital, University of Edinburgh.

\section{Availability of data and materials}

The datasets supporting the conclusions of this article are available in the GEO repository under accession numbers GSE147375 and GSE146892.

\section{Declarations}

Ethics approval and consent to participate

Experiments were carried out in accordance with University of Edinburgh guidelines and the UK Home Office Animals (Scientific Procedures) Act 1986.

\section{Consent for publication}

Not applicable.

\section{Competing interests}

Nothing to disclose.

\begin{abstract}
Author details
${ }^{1}$ University/British Heart Foundation Centre for Cardiovascular Science, University of Edinburgh, The Queens Medical Research Institute, 47 Little France Crescent, Edinburgh EH16 4TJ, UK. ${ }^{2}$ Department of Biochemistry III, University of Regensburg, 93040 Regensburg, Germany. ${ }^{3}$ MRC Centre for Reproductive Health, University of Edinburgh, The Queens Medical Research Institute, 47 Little France Crescent, Edinburgh EH16 4TJ, UK. ${ }^{4}$ Centre for Clinical Brain Sciences, University of Edinburgh, Chancellor's Building, 49 Little France Crescent, Edinburgh EH16 4SB, UK. ${ }^{5}$ The Douglas Research Center, 6875 Boulevard LaSalle, Montréal, QC H4H 1R3, Canada.
\end{abstract}

Received: 29 March 2021 Accepted: 17 June 2021

Published online: 30 June 2021

\section{References}

1. Carr CP, Martins CMS, Stingel AM, Lemgruber VB, Juruena MF. The role of early life stress in adult psychiatric disorders: a systematic review according to childhood trauma subtypes. J Nerv Ment Dis. 2013;201:1007-20. https://doi.org/10.1097/NMD.0000000000000049.

2. Targum SD, Nemeroff $C B$. The effect of early life stress on adult psychiatric disorders. Innov Clin Neurosci. 2019;16:35.

3. Lähdepuro A, Savolainen K, Lahti-Pulkkinen M, Eriksson JG, Lahti J, Tuovinen $\mathrm{S}$, et al. The impact of early life stress on anxiety symptoms in late adulthood. Sci Rep. 2019;9:4395. https://doi.org/10.1038/ s41598-019-40698-0.

4. Williams L, Debattista C, Duchemin A, Schatzberg A, Nemeroff C. Childhood trauma predicts antidepressant response in adults with major depression: data from the randomized international study to predict optimized treatment for depression. Transl Psychiatry. 2016. https://doi. org/10.1038/TP.2016.61

5. Nanni V, Uher R, Danese A. Childhood maltreatment predicts unfavorable course of illness and treatment outcome in depression: a meta-analysis. Am J Psychiatry. 2012. https://doi.org/10.1176/APPI.AJP.2011.11020335.

6. Agorastos A, Pervanidou P, Chrousos GP, Baker DG. Developmental trajectories of early life stress and trauma: a narrative review on neurobiological aspects beyond stress system dysregulation. Front psychiatry. 2019;10:118. https://doi.org/10.3389/fpsyt.2019.00118.

7. Heim C, Binder EB. Current research trends in early life stress and depression: Review of human studies on sensitive periods, gene-environment interactions, and epigenetics. Exp Neurol. 2012;233:102-11. https://doi. org/10.1016/J.EXPNEUROL.2011.10.032.

8. Fitzgerald E, Parent C, Kee MZL, Meaney MJ. Maternal distress and offspring neurodevelopment: challenges and opportunities for pre-clinical research models. Front Hum Neurosci. 2021;15: 635304. https://doi.org/ 10.3389/fnhum.2021.635304.

9. Van den Bergh BRH, Van Calster B, Smits T, Van Huffel S, Lagae L. Antenatal maternal anxiety is related to HPA-Axis dysregulation and self-reported depressive symptoms in adolescence: a prospective study on the fetal origins of depressed mood. Neuropsychopharmacology. 2008;33:536-45. https://doi.org/10.1038/sj.npp.1301450.

10. O'Connor TG, Heron J, Golding J, Glover V, ALSPAC Study Team. Maternal antenatal anxiety and behavioural/emotional problems in children: a test of a programming hypothesis. J Child Psychol Psychiatry. 2003. https:// doi.org/10.1111/1469-7610.00187. 
11. Brummelte S, Grunau RE, Chau V, Poskitt KJ, Brant R, Vinall J, et al. Procedural pain and brain development in premature newborns. Ann Neurol. 2012;71:385-96. https://doi.org/10.1002/ana.22267.

12. Brummelte S, Chau CMY, Cepeda IL, Degenhardt A, Weinberg J, Synnes $A R$, et al. Cortisol levels in former preterm children at school age are predicted by neonatal procedural pain-related stress. Psychoneuroendocrinology. 2015;51:151-63. https://doi.org/10.1016/j.psyneuen.2014.09. 018.

13. van Bodegom M, Homberg JR, Henckens MJAG. Modulation of the hypothalamic-pituitary-adrenal axis by early life stress exposure. Front Cell Neurosci. 2017;11:87. https://doi.org/10.3389/fncel.2017.00087.

14. Weaver ICG, Cervoni N, Champagne FA, D'Alessio AC, Sharma S, Seckl $\mathrm{JR}$, et al. Epigenetic programming by maternal behavior. Nat Neurosci. 2004;7:847-54. https://doi.org/10.1038/nn1276.

15. Gunn BG, Cunningham L, Cooper MA, Corteen NL, Seifi M, Swinny JD, et al. Dysfunctional astrocytic and synaptic regulation of hypothalamic glutamatergic transmission in a mouse model of early-life adversity: relevance to neurosteroids and programming of the stress response. J Neurosci. 2013;33:19534-54. https://doi.org/10.1523/JNEUROSCI.1337-13. 2013.

16. Marrocco J, Gray JD, Kogan JF, Einhorn NR, O'Cinneide EM, Rubin TG, et al. Early life stress restricts translational reactivity in CA3 neurons associated with altered stress responses in adulthood. Front Behav Neurosci. 2019;13:157. https://doi.org/10.3389/fnbeh.2019.00157.

17. Murgatroyd C, Patchev AV, Wu Y, Micale V, Bockmühl Y, Fischer D, et al. Dynamic DNA methylation programs persistent adverse effects of earlylife stress. Nat Neurosci. 2009;12:1559-66. https://doi.org/10.1038/nn. 2436.

18. Bale TL, Baram TZ, Brown AS, Goldstein JM, Insel TR, McCarthy MM, et al. Early life programming and neurodevelopmental disorders. Biol Psychiatry. 2010;68:314-9. https://doi.org/10.1016/j.biopsych.2010.05.028.

19. Baker-Andresen D, Ratnu VS, Bredy TW. Dynamic DNA methylation: a prime candidate for genomic metaplasticity and behavioral adaptation. Trends Neurosci. 2013;36:3-13. https://doi.org/10.1016/J.TINS.2012.09. 003.

20. Gassen NC, Fries GR, Zannas AS, Hartmann J, Zschocke J, Hafner K, et al. Chaperoning epigenetics: FKBP51 decreases the activity of DNMT1 and mediates epigenetic effects of the antidepressant paroxetine. Sci Signal. 2015. https://doi.org/10.1126/scisignal.aac7695.

21. Guo JU, Ma DK, Mo H, Ball MP, Jang M-H, Bonaguidi MA, et al. Neuronal activity modifies the DNA methylation landscape in the adult brain. Nat Neurosci. 2011;14:1345-51. https://doi.org/10.1038/nn.2900.

22. Labonté B, Suderman M, Maussion G, Navaro L, Yerko V, Mahar I, et al. Genome-wide epigenetic regulation by early-life trauma. Arch Gen Psychiatry. 2012. https://doi.org/10.1001/archgenpsychiatry.2011.2287.

23. Klengel T, Mehta D, Anacker C, Rex-Haffner M, Pruessner JC, Pariante CM, et al. Allele-specific FKBP5 DNA demethylation mediates gene-childhood trauma interactions. Nat Neurosci. 2013;16:33-41. https://doi.org/ 10.1038/nn.3275

24. Torres-Berrío A, Issler O, Parise EM, Nestler EJ. Unraveling the epigenetic landscape of depression: focus on early life stress. Dialogues Clin Neurosci. 2019;21:341-57. https://doi.org/10.31887/DCNS.2019.21.4/enestler.

25. Duvanel CB, Fawer CL, Cotting J, Hohlfeld P, Matthieu JM. Long-term effects of neonatal hypoglycemia on brain growth and psychomotor development in small-for-gestational-age preterm infants. J Pediatr. 1999;134:492-8. https://doi.org/10.1016/s0022-3476(99)70209-x.

26. Fitzgerald E, Boardman JP, Drake AJ. Early life stress and LPS interact to modify the mouse cortical transcriptome in the neonatal period. Brain Behav Immun Heal. 2021;13: 100219. https://doi.org/10.1016/j.bbih.2021. 100219.

27. Walf AA, Frye CA. The use of the elevated plus maze as an assay of anxiety-related behavior in rodents. Nat Protoc. 2007;2:322-8. https://doi. org/10.1038/nprot.2007.44.

28. Seibenhener ML, Wooten MC. Use of the Open Field Maze to measure locomotor and anxiety-like behavior in mice. J Vis Exp. 2015. https://doi. org/10.3791/52434

29. Can A, Dao DT, Terrillion CE, Piantadosi SC, Bhat S, Gould TD. The tail suspension test. J Vis Exp. 2012. https://doi.org/10.3791/3769.

30. Moll P, Ante M, Seitz A, Reda T. QuantSeq $3^{\prime}$ mRNA sequencing for RNA quantification. Nat Methods. 2014;11:i-iii. https://doi.org/10.1038/ nmeth.f.376.
31. Ma F, Fuqua BK, Hasin Y, Yukhtman C, Vulpe CD, Lusis AJ, et al. A comparison between whole transcript and 3'RNA sequencing methods using Kapa and Lexogen library preparation methods. BMC Genomics. 2019;20:9. https://doi.org/10.1186/s12864-018-5393-3.

32. Afgan E, Baker D, Batut B, van den Beek M, Bouvier D, Čech M, et al. The Galaxy platform for accessible, reproducible and collaborative biomedical analyses: 2018 update. Nucleic Acids Res. 2018;46:W537-44. https://doi. org/10.1093/nar/gky379.

33. The Gene Ontology Consortium. The Gene Ontology Resource: 20 years and still GOing strong. Nucleic Acids Res. 2019;47:D330-8. https://doi. org/10.1093/nar/gky1055.

34. Ashburner M, Ball CA, Blake JA, Botstein D, Butler H, Cherry JM, et al. Gene ontology: tool for the unification of biology. Gene Ontology Consortium Nat Genet. 2000;25:25-9. https://doi.org/10.1038/75556.

35. Chen Y, Lun ATL, Smyth GK. From reads to genes to pathways: differential expression analysis of RNA-Seq experiments using Rsubread and the edgeR quasi-likelihood pipeline. F1000Research. 2016;5:1438. https://doi. org/10.12688/f1000research.8987.2.

36. Conesa A, Madrigal P, Tarazona S, Gomez-Cabrero D, Cervera A, McPherson A, et al. A survey of best practices for RNA-seq data analysis. Genome Biol. 2016;17:13. https://doi.org/10.1186/s13059-016-0881-8.

37. Kwon AT, Arenillas DJ, Hunt RW, Wasserman WW. oPOSSUM-3: advanced analysis of regulatory Motif over-representation across genes or ChIP-Seq datasets. G3 Genes Genom Genet. 2012;2:987. https://doi.org/10.1534/ G3.112.003202.

38. Thomson JP, Fawkes A, Ottaviano R, Hunter JM, Shukla R, Mjoseng HK, et al. DNA immunoprecipitation semiconductor sequencing (DIP-SC-seq) as a rapid method to generate genome wide epigenetic signatures. Sci Rep. 2015;5:9778. https://doi.org/10.1038/srep09778.

39. Zhang Y, Liu T, Meyer CA, Eeckhoute J, Johnson DS, Bernstein BE, et al. Model-based Analysis of ChIP-Seq (MACS). Genome Biol. 2008:9:R137. https://doi.org/10.1186/gb-2008-9-9-r137.

40. Rory Stark and Gord Brown. DiffBind: Differential binding analysis of ChIPSeq peak data. http://bioconductor.org/packages/release/bioc/ vignettes/DiffBind/inst/doc/DiffBind.pdf. Accessed 1 Mar 2020.

41. Heinz S, Benner C, Spann N, Bertolino E, Lin YC, Laslo P, et al. Simple combinations of lineage-determining transcription factors prime cisregulatory elements required for macrophage and B cell identities. Mol Cell. 2010;38:576-89. https://doi.org/10.1016/j.molcel.2010.05.004.

42. Zhang Y, Hu W. NFkB signaling regulates embryonic and adult neurogenesis. Front Biol (Beijing). 2012. https://doi.org/10.1007/s11515-012-1233-z.

43. Yuen TJ, Silbereis JC, Griveau A, Chang SM, Daneman R, Fancy SPJ, et al. Oligodendrocyte-encoded HIF function couples postnatal myelination and white matter angiogenesis. Cell. 2014;158:383-96. https://doi.org/10. 1016/j.cell.2014.04.052.

44. Qin S, Liu M, Niu W, Zhang C-L. Dysregulation of Kruppel-like factor 4 during brain development leads to hydrocephalus in mice. Proc Natl Acad Sci U S A. 2011;108:21117-21. https://doi.org/10.1073/pnas.1112351109.

45. Bialkowska AB, Yang VW, Mallipattu SK. Krüppel-like factors in mammalian stem cells and development. Development. 2017;144:737-54. https://doi. org/10.1242/dev.145441.

46. Jones PA. Functions of DNA methylation: islands, start sites, gene bodies and beyond. Nat Rev Genet. 2012;13:484-92. https://doi.org/10.1038/ nrg3230.

47. Bonapersona V, Kentrop J, Van Lissa CJ, van der Veen R, Joëls M, Sarabdjitsingh RA. The behavioral phenotype of early life adversity: A 3-level metaanalysis of rodent studies. Neurosci Biobehav Rev. 2019;102:299-307. https://doi.org/10.1016/j.neubiorev.2019.04.021.

48. Wang D, Levine JLS, Avila-Quintero V, Bloch M, Kaffman A. Systematic review and meta-analysis: effects of maternal separation on anxiety-like behavior in rodents. Transl Psychiatry. 2020;10:174. https://doi.org/10. 1038/s41398-020-0856-0.

49. Bondar NP, Lepeshko AA, Reshetnikov W. Effects of early-life stress on social and anxiety-like behaviors in adult mice: sex-specific effects. Behav Neurol. 2018;2018:1-13. https://doi.org/10.1155/2018/1538931.

50. Kosten TA, Kim JJ, Lee HJ. Early life manipulations alter learning and memory in rats. Neurosci Biobehav Rev. 2012;36:1985-2006. https://doi. org/10.1016/j.neubiorev.2012.07.003. 
51. Benetti F, Mello PB, Bonini JS, Monteiro S, Cammarota M, Izquierdo I. Early postnatal maternal deprivation in rats induces memory deficits in adult life that can be reversed by donepezil and galantamine. Int J Dev Neurosci. 2009;27:59-64. https://doi.org/10.1016/j.ijdevneu.2008.09.200.

52. Champagne DL, Bagot RC, van Hasselt F, Ramakers G, Meaney MJ, de Kloet ER, et al. Maternal care and hippocampal plasticity: evidence for experience-dependent structural plasticity, altered synaptic functioning, and differential responsiveness to glucocorticoids and stress. J Neurosci. 2008;28:6037-45. https://doi.org/10.1523/JNEUROSCI.0526-08.2008.

53. Steimer T. The biology of fear- and anxiety-related behaviors. Dialogues Clin Neurosci. 2002;4:231-49. http://www.ncbi.nlm.nih.gov/pubmed/ 22033741.

54. Spratt EG, Nicholas JS, Brady KT, Carpenter LA, Hatcher CR, Meekins KA, et al. Enhanced cortisol response to stress in children in autism. J Autism Dev Disord. 2012;42:75-81. https://doi.org/10.1007/s10803-011-1214-0.

55. Schifani $\mathrm{C}$, Tseng $\mathrm{H}-\mathrm{H}$, Kenk M, Tagore A, Kiang M, Wilson AA, et al. Cortical stress regulation is disrupted in schizophrenia but not in clinical high risk for psychosis. Brain. 2018;141:2213-24. https://doi.org/10.1093/brain/ awy133.

56. Berghorst LH, Kumar P, Greve DN, Deckersbach T, Ongur D, Dutra SJ, et al. Stress and reward processing in bipolar disorder: a functional magnetic resonance imaging study. Bipolar Disord. 2016;18:602-11. https://doi.org/ 10.1111/bdi.12444

57. Buske-Kirschbaum A, Krieger S, Wilkes C, Rauh W, Weiss S, Hellhammer DH. Hypothalamic-pituitary-adrenal axis function and the cellular immune response in former preterm children. J Clin Endocrinol Metab. 2007;92:3429-35. https://doi.org/10.1210/jc.2006-2223.

58. Lee J, Fried R, Thayer Z, Kuzawa CW. Preterm delivery as a predictor of diurnal cortisol profiles in adulthood: evidence from Cebu. Philippines Am J Hum Biol. 2014;26:598-602. https://doi.org/10.1002/ajhb.22569.

59. Teicher MH, Samson JA, Anderson CM, Ohashi K. The effects of childhood maltreatment on brain structure, function and connectivity. Nat Rev Neurosci. 2016;17:652-66. https://doi.org/10.1038/nrn.2016.111.

60. Pechtel P, Pizzagalli DA. Effects of early life stress on cognitive and affective function: an integrated review of human literature. Psychopharmacology. 2011;214:55-70. https://doi.org/10.1007/s00213-010-2009-2.

61. Sonuga-Barke EJS, Kennedy M, Kumsta R, Knights N, Golm D, Rutter M, et al. Child-to-adult neurodevelopmental and mental health trajectories after early life deprivation: the young adult follow-up of the longitudinal English and Romanian Adoptees study. Lancet (London, England). 2017;389:1539-48. https://doi.org/10.1016/S0140-6736(17)30045-4.

62. Mackes NK, Golm D, Sarkar S, Kumsta R, Rutter M, Fairchild G, et al. Early childhood deprivation is associated with alterations in adult brain structure despite subsequent environmental enrichment. Proc Natl Acad Sci U S A. 2020;117:641-9. https://doi.org/10.1073/pnas.1911264116.

63. Franz AP, Bolat GU, Bolat H, Matijasevich A, Santos IS, Silveira RC, et al. Attention-deficit/hyperactivity disorder and very preterm/very low birth weight: a meta-analysis. Pediatrics. 2018;141: e20171645. https://doi.org/ 10.1542/peds.2017-1645.

64. Spiers H, Hannon E, Schalkwyk LC, Smith R, Wong CCY, O'Donovan MC, et al. Methylomic trajectories across human fetal brain development. Genome Res. 2015;25:338-52. https://doi.org/10.1101/gr.180273.114.

65. Ladd-Acosta C, Hansen KD, Briem E, Fallin MD, Kaufmann WE, Feinberg AP. Common DNA methylation alterations in multiple brain regions in autism. Mol Psychiatry. 2014;19:862-71. https://doi.org/10.1038/mp.2013. 114.

66. Hannon E, Dempster E, Viana J, Burrage J, Smith AR, Macdonald R, et al. An integrated genetic-epigenetic analysis of schizophrenia: evidence for co-localization of genetic associations and differential DNA methylation. Genome Biol. 2016;17:176. https://doi.org/10.1186/s13059-016-1041-x.

67. Mooney MA, Ryabinin P, Wilmot B, Bhatt P, Mill J, Nigg JT. Large epigenome-wide association study of childhood ADHD identifies peripheral DNA methylation associated with disease and polygenic risk burden. Transl Psychiatry. 2020;10:8. https://doi.org/10.1038/s41398-020-0710-4

68. Barnett Burns S, Almeida D, Turecki G. The Epigenetics of Early Life Adversity: Current Limitations and Possible Solutions. In: Progress in molecular biology and translational science. 2018. p. 343-425. https://doi.org/10. 1016/bs.pmbts.2018.01.008

69. Mehta D, Klengel T, Conneely KN, Smith AK, Altmann A, Pace TW, et al. Childhood maltreatment is associated with distinct genomic and epigenetic profiles in posttraumatic stress disorder. Proc Natl Acad Sci U S A. 2013;110:8302-7. https://doi.org/10.1073/pnas.1217750110.

70. Feng J, Zhou Y, Campbell SL, Le T, Li E, Sweatt JD, et al. Dnmt1 and Dnmt3a maintain DNA methylation and regulate synaptic function in adult forebrain neurons. Nat Neurosci. 2010;13:423-30. https://doi.org/10. 1038/nn.2514.

71. Schmidt MV. Stress-hyporesponsive period. Stress Physiol Biochem Pathol. 2019. https://doi.org/10.1016/B978-0-12-813146-6.00004-7.

72. Chawanpaiboon S, Vogel JP, Moller A-B, Lumbiganon P, Petzold M, Hogan $D$, et al. Global, regional, and national estimates of levels of preterm birth in 2014: a systematic review and modelling analysis. Lancet Glob Heal. 2019;7:e37-46. https://doi.org/10.1016/S2214-109X(18)30451-0.

73. Martin JA OM. Describing the Increase in Preterm Births in the United States, 2014-2016. 2018. https://www.cdc.gov/nchs/products/databriefs/

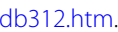

74. Bhutta AT, Cleves MA, Casey PH, Cradock MM, Anand KJS. Cognitive and behavioral outcomes of school-aged children who were born preterm: a meta-analysis. JAMA. 2002;288:728-37. http://www.ncbi.n/m.nih.gov/ pubmed/12169077.

75. Schendel D, Bhasin TK. Birth weight and gestational age characteristics of children with autism, including a comparison with other developmental disabilities. Pediatrics. 2008;121:1155-64. https://doi.org/10.1542/peds. 2007-1049.

76. Dalman C, Allebeck P, Cullberg J, Grunewald C, Köster M. Obstetric complications and the risk of schizophrenia: a longitudinal study of a national birth cohort. Arch Gen Psychiatry. 1999;56:234-40. http://www.ncbi.nlm. nih.gov/pubmed/10078500.

77. Nosarti C, Reichenberg A, Murray RM, Cnattingius S, Lambe MP, Yin L, et al. Preterm birth and psychiatric disorders in young adult life. Arch Gen Psychiatry. 2012;69:610-7. https://doi.org/10.1001/archgenpsychiatry. 2011.1374.

78. Workman AD, Charvet CJ, Clancy B, Darlington RB, Finlay BL. Modeling transformations of neurodevelopmental sequences across mammalian species. J Neurosci. 2013;33:7368-83. https://doi.org/10.1523/JNEUROSCI. 5746-12.2013.

79. Sparrow S, Manning JR, Cartier J, Anblagan D, Bastin ME, Piyasena C, et al. Epigenomic profiling of preterm infants reveals DNA methylation differences at sites associated with neural function. Transl Psychiatry. 2016;6: e716. https://doi.org/10.1038/tp.2015.210.

80. Johnson S, Kochhar P, Hennessy E, Marlow N, Wolke D, Hollis C. Antecedents of attention-deficit/hyperactivity disorder symptoms in children born extremely preterm. J Dev Behav Pediatr. 2016;37:285-97. https://doi. org/10.1097/DBP.0000000000000298.

81. Mueller BR, Bale TL. Sex-specific programming of offspring emotionality after stress early in pregnancy. J Neurosci. 2008;28:9055-65. https://doi. org/10.1523/JNEUROSCI.1424-08.2008.

82. Llorente R, Miguel-Blanco C, Aisa B, Lachize S, Borcel E, Meijer OC, et al. Long term sex-dependent psychoneuroendocrine effects of maternal deprivation and juvenile unpredictable stress in rats. J Neuroendocrinol. 2011;23:329-44. https://doi.org/10.1111/j.1365-2826.2011.02109.x.

83. Goodwill HL, Manzano-Nieves G, Gallo M, Lee H-I, Oyerinde E, Serre T, et al. Early life stress leads to sex differences in development of depressive-like outcomes in a mouse model. Neuropsychopharmacology. 2019;44:711-20. https://doi.org/10.1038/s41386-018-0195-5.

84. Bale TL, Epperson CN. Sex differences and stress across the lifespan. Nat Neurosci. 2015;18:1413-20. https://doi.org/10.1038/nn.4112.

85. Deaton AM, Bird A. CpG islands and the regulation of transcription. Genes Dev. 2011;25:1010-22. https://doi.org/10.1101/gad.2037511.

86. Yim YY, Teague CD, Nestler EJ. In vivo locus-specific editing of the neuroepigenome. Nat Rev Neurosci. 2020;21:471-84. https://doi.org/10.1038/ s41583-020-0334-y.

87. Hanson JL, Nacewicz BM, Sutterer MJ, Cayo AA, Schaefer SM, Rudolph $K D$, et al. Behavioral problems after early life stress: Contributions of the hippocampus and amygdala. Biol Psychiatry. 2015;77:314-23.

88. Fareri DS, Tottenham N. Effects of early life stress on amygdala and striatal development. Dev Cogn Neurosci. 2016;19:233-47.

\section{Publisher's Note}

Springer Nature remains neutral with regard to jurisdictional claims in published maps and institutional affiliations. 